\title{
138
}

THE USE OF MULTIPLE MEASUREMENTS

IN TAXONOMIC PROBLEMS

Author's Note (CMS 32.178a)

* Reproduced from "Contributions to Mathematical Statistics" (1950) by permission of John Wiley \& Sons, Inc.

This was written to embody the working of a practical numerical example arising in plant taxonomy, in which the concept of a discriminant function seems to be of immediate service. 


\title{
THE USE OF MULTIPLE MEASUREMENTS IN TAXONOMIC PROBLEMS
}

\author{
BY R. A. FISHER, Sc.D., F.R.S.

\section{Discriminant functions}

WHEN two or more populations have been measured in several characters, $x_{1}, \ldots, x_{s}$, special interest attaches to certain linear functions of the measurements by which the populations are best discriminated. At the author's suggestion use has already been made of this fact in craniometry $(a)$ by Mr E. S. Martin, who has applied the principle to the sex differences in measurements of the mandible, and $(b)$ by Miss Mildred Barnard, who showed how to obtain from a series of dated series the particular compound of cranial measurements showing most distinctly a progressive or secular trend. In the present paper the application of the same principle will be illustrated on a taxonomic problem; some questions connected with the precision of the processes employed will also be discussed.

\section{Arithmetical procendre}

Table I shows measurements of the flowers of fifty plants each of the two species Iris setosa and $I$. versicolor, found growing together in the same colony and measured by Dr E. Anderson, to whom I am indebted for the use of the data. Four flower measurements are given. We shall first consider the question: What linear function of the four measurements

$$
X=\lambda_{1} x_{1}+\lambda_{2} x_{2}+\lambda_{3} x_{3}+\lambda_{4} x_{4}
$$

will maximize the ratio of the difference between the specific means to the standard deviations within species? The observed means and their differences are shown in Table II. We may represent the differences by $d_{p}$, where $p=1,2,3$ or 4 for the four measurements.

The sums of squares and products of deviations from the specific means are shown in Table III. Since fifty plants of each species were used these sums contain 98 degrees of freedom. We may represent these sums of squares or products by $S_{p q}$, where $p$ and $q$ take independently the values $1,2,3$ and 4 .

Then for any linear function, $X$, of the measurements, as defined above, the difference between the means of $X$ in the two species is

$$
D=\lambda_{1} d_{1}+\lambda_{2} d_{2}+\lambda_{3} d_{3}+\lambda_{4} d_{4},
$$

while the variance of $X$ within species is proportional to

$$
S=\sum_{p=1}^{4} \sum_{q=1}^{4} \lambda_{p} \lambda_{q} S_{p q}
$$

The particular linear function which best discriminates the two species will be one for 
Table I

\begin{tabular}{|c|c|c|c|c|c|c|c|c|c|c|c|}
\hline \multicolumn{4}{|c|}{ Iris setosa } & \multicolumn{4}{|c|}{ Iris versicolor } & \multicolumn{4}{|c|}{ Iris virginica } \\
\hline $\begin{array}{l}\text { Sepal } \\
\text { length }\end{array}$ & $\begin{array}{l}\text { Sepal } \\
\text { width }\end{array}$ & $\begin{array}{l}\text { Petal } \\
\text { length }\end{array}$ & $\begin{array}{l}\text { Petal } \\
\text { width }\end{array}$ & $\begin{array}{l}\text { Sepal } \\
\text { length }\end{array}$ & $\begin{array}{l}\text { Sepal } \\
\text { width }\end{array}$ & $\begin{array}{l}\text { Petal } \\
\text { length }\end{array}$ & $\begin{array}{l}\text { Petal } \\
\text { width }\end{array}$ & $\begin{array}{l}\text { Sepal } \\
\text { length }\end{array}$ & $\begin{array}{l}\text { Sepal } \\
\text { width }\end{array}$ & $\begin{array}{l}\text { Petal } \\
\text { length }\end{array}$ & $\begin{array}{l}\text { Petal } \\
\text { width }\end{array}$ \\
\hline $5 \cdot 1$ & $3 \cdot 5$ & $1 \cdot 4$ & $0 \cdot 2$ & $7 \cdot 0$ & $3 \cdot 2$ & $4 \cdot 7$ & 1.4 & $6 \cdot 3$ & $3 \cdot 3$ & 6.0 & 2.5 \\
\hline $4 . \hat{9}$ & $3 \cdot 0$ & 1.4 & $0 \cdot 2$ & 6.4 & $3 \cdot 2$ & 4.5 & 1.5 & $5 \cdot 8$ & 27 & $5 \cdot 1$ & $1 \cdot 9$ \\
\hline $4 \cdot 7$ & $3 \cdot 2$ & $1 \cdot 3$ & $0 \cdot 2$ & 69 & $3 \cdot 1$ & $4 \cdot 9$ & 1.5 & $7 \cdot I$ & $3 \cdot 0$ & $5 \cdot 9$ & $2 \cdot 1$ \\
\hline $4 \cdot 6$ & $3 \cdot 1$ & $1 \cdot 5$ & 0.2 & $5 \cdot 5$ & $2 \cdot 3$ & $4 \cdot 0$ & $1 \cdot 3$ & $6 \cdot 3$ & $2 \cdot 9$ & $5 \cdot 6$ & 1.8 \\
\hline $5 \cdot 0$ & $3 \cdot 6$ & $\mathrm{I} \cdot 4$ & $0 . \overline{2}$ & $6 \cdot 5$ & $2 \cdot 8$ & $4 \cdot 6$ & $1 \cdot 5$ & 6.5 & $3 \cdot 0$ & $5 \cdot 8$ & $2 \cdot 2$ \\
\hline $5 \cdot 4$ & 3.9 & $1 \cdot 7$ & $0-4$ & $5 \cdot 7$ & $2 \cdot 8$ & $4 \cdot 5$ & $1 \cdot 3$ & $7 \cdot 6$ & 3.0 & $6 \cdot 6$ & $2 \cdot 1$ \\
\hline $4 \cdot 6$ & $3 \cdot 4$ & $1 \cdot 4$ & 0.3 & $6 \cdot 3$ & $3 \cdot 3$ & $4 \cdot 7$ & $1 \cdot 6$ & 49 & $2 \cdot 5$ & 4.5 & 1.7 \\
\hline $5 \cdot 0$ & $3 \cdot 4$ & 1.5 & 0.2 & $4 \cdot 9$ & $2 \cdot 4$ & $3 \cdot 3$ & $1 \cdot 0$ & $7 \cdot 3$ & $2 \cdot 9$ & $6 \cdot 3$ & 1.8 \\
\hline 4.4 & $2 \cdot 9$ & $1 \cdot 4$ & 0.2 & $6 \cdot 6$ & 2.9 & $4 \cdot 6$ & $1 \cdot 3$ & 6.7 & $2 \cdot 5$ & $5 \cdot 8$ & 1.8 \\
\hline 4.9 & $3 \cdot 1$ & 1.5 & 0.1 & $5 \cdot 2$ & 2.7 & $3 \cdot 9$ & $1 \cdot 4$ & $7 \cdot 2$ & 3.6 & $6 \cdot \mathrm{I}$ & $2 \cdot 5$ \\
\hline$\tilde{5} \cdot 4$ & 3.7 & 1.5 & 0.2 & $5 \cdot 0$ & $2 \cdot 0$ & 3.5 & 1.0 & 6.5 & $3 \cdot 2$ & $5 \cdot 1$ & $2 \cdot 0$ \\
\hline $4 \cdot 8$ & $3 \cdot 4$ & $1 \cdot 6$ & $0 \cdot 2$ & $5 \cdot 9$ & $3 \cdot 0$ & $4 \cdot 2$ & 1.5 & $6 \cdot 4$ & $2 \cdot 7$ & $5-3$ & $1 \cdot 9$ \\
\hline 4.8 & $3 \cdot 0$ & $1 \cdot 4$ & $0 \cdot 1$ & $6 \cdot 0$ & $2 \cdot 2$ & $4 \cdot 0$ & $1 \cdot 0$ & $6 \cdot 8$ & $3 \cdot 0$ & $5 \cdot 5$ & $2 \cdot 1$ \\
\hline $4 \cdot 3$ & $3 \cdot 0$ & $1 \cdot 1$ & 0.1 & $6 \cdot 1$ & $2 \cdot 9$ & $4 \cdot 7$ & $1 \cdot 4$ & $5 \cdot 7$ & $2 \cdot 5$ & $5 \cdot 0$ & $2 \cdot 0$ \\
\hline $5 \cdot 8$ & $4 \cdot 0$ & $1 \cdot 2$ & 0.2 & $5 \cdot 6$ & $2 \cdot 9$ & $3 \cdot 6$ & $1 \cdot 3$ & $5 \cdot 8$ & $2 \cdot 8$ & $5 \cdot 1$ & $2 \cdot 4$ \\
\hline $5 \cdot 7$ & $4 \cdot 4$ & 1.5 & $0 \cdot 4$ & $6 \cdot 7$ & $3 \cdot 1$ & $4 \cdot 4$ & $1 \cdot 4$ & $6 \cdot 4$ & $3 \cdot 2$ & $5 \cdot 3$ & $2 \cdot 3$ \\
\hline $5 \cdot 4$ & $3 \cdot 9$ & $1 \cdot 3$ & $0 \cdot \tilde{4}$ & $5 \cdot 6$ & 3.0 & $4 \cdot 5$ & $1 \cdot 5$ & $6 \cdot 5$ & $3 \cdot 0$ & $5 \cdot 5$ & 1.8 \\
\hline $5 \cdot \hat{1}$ & 3.5 & $1 \cdot 4$ & $0 \cdot 3$ & $5 \cdot 8$ & $2 \cdot 7$ & $4 \cdot 1$ & $1 \cdot 0$ & 7.7 & $3 \cdot 8$ & $6 \cdot 7$ & $2 \cdot 2$ \\
\hline $5 \cdot 7$ & $3 \cdot 8$ & 1.7 & 0.3 & $6 \cdot 2$ & $2 \cdot 2$ & $4 \cdot 5$ & 1.5 & 7.7 & $2 \cdot 6$ & $6 \cdot 9$ & $2 \cdot 3$ \\
\hline $5 \cdot 1$ & $3 \cdot 8$ & 1.5 & 0.3 & 56 & $2 \cdot 5$ & $3 \cdot 9$ & $1 \cdot 1$ & $6 \cdot 0$ & $2 \cdot 2$ & $5 \cdot 0$ & 1.5 \\
\hline $5 \cdot 4$ & $3 \cdot 4$ & 1.7 & 0.2 & $5 \cdot 9$ & $3 \cdot 2$ & $4 \cdot 8$ & 1.8 & $6 \cdot 9$ & $3 \cdot 2$ & $5 \cdot 7$ & $2 \cdot 3$ \\
\hline $5 \cdot I$ & $3 \cdot 7$ & 1.5 & $0 \cdot 4$ & $6 \cdot 1$ & $2 \cdot 8$ & 40 & $1 \cdot 3$ & $5 \cdot 6$ & $2 \cdot 8$ & $4 \cdot 9$ & $2 \cdot 0$ \\
\hline $4 \cdot \hat{6}$ & $3 \cdot 6$ & $1 \cdot 0$ & 0.2 & $6 \cdot 3$ & $2 \cdot 5$ & $4 \cdot 9$ & 1.5 & $7 \cdot 7$ & $2 \cdot 8$ & 6.7 & $2 \cdot 0$ \\
\hline $5 \cdot 1$ & $3 \cdot 3$ & 1.7 & $0 \cdot 5$ & $6 \cdot 1$ & 2.8 & $4 \cdot 7$ & I. 2 & $6 \cdot 3$ & $2 \cdot 7$ & $4 \cdot 9$ & 1.8 \\
\hline 4.8 & $3 \cdot 4$ & 1.9 & $0 \cdot 2$ & 6.4 & $2 \cdot 9$ & $4 \cdot 3$ & $1 \cdot 3$ & 6.7 & $3 \cdot 3$ & 5.7 & $2 \cdot 1$ \\
\hline 5.0 & 30 & $1 \cdot 6$ & $0 \cdot 2$ & $6 \cdot 6$ & $3 \cdot 0$ & $4 \cdot 4$ & $1 \cdot 4$ & $7 \cdot 2$ & $3 \cdot 2$ & 6.0 & 1.8 \\
\hline $5 \cdot 0$ & $3 \cdot 4$ & $1 \cdot 6$ & $0 \cdot 4$ & 6.8 & $2 \cdot 8$ & $4 \cdot 8$ & $1 \cdot 4$ & $6 \cdot 2$ & 2.8 & 4.8 & $1 \cdot 8$ \\
\hline $5 \cdot 2$ & $3 \cdot 5$ & 1.5 & 0.2 & 6.7 & $3 \cdot 0$ & $5 \cdot 0$ & 1.7 & $6 \cdot I$ & 3.0 & $4 \cdot 9$ & $1 \cdot 8$ \\
\hline $5 \cdot \overline{2}$ & $3 \cdot 4$ & $1 \cdot 4$ & $0 \cdot 2$ & $6 \cdot 0$ & $2 \cdot 9$ & 4.5 & 1.5 & $6 \cdot 4$ & 2.8 & $5 \cdot 6$ & $2 \cdot 1$ \\
\hline $4 \cdot 7$ & 3.2 & $1 \cdot 6$ & $0 \cdot 2$ & $5 \cdot 7$ & $2 \cdot 6$ & $3 \cdot 5$ & $1 \cdot 0$ & $7 \cdot 2$ & $3 \cdot 0$ & $5 \cdot 8$ & 1.6 \\
\hline $4 \cdot 8$ & $3 \cdot 1$ & $1 \cdot 6$ & 0.2 & $5 \cdot 5$ & $2 \cdot 4$ & $3 \cdot 8$ & $1 \cdot 1$ & $7 \cdot \overline{4}$ & $2 \cdot 8$ & $6 \cdot 1$ & $1 \cdot 9$ \\
\hline $5 \cdot 4$ & $3 \cdot 4$ & 1.5 & $0-4$ & $5 \cdot 5$ & $2 \cdot 4$ & $3 \cdot 7$ & 1.0 & $7 \cdot 9$ & $3 \cdot 8$ & 6.4 & $2 \cdot 0$ \\
\hline $5 \cdot 2$ & $4 \cdot \hat{1}$ & 1.5 & $0 \cdot \overline{1}$ & $5 \cdot 8$ & $2 \cdot 7$ & $3 \cdot 9$ & 1.2 & 6.4 & 2.8 & $5 \cdot 6$ & $2 \cdot 2$ \\
\hline $5 \cdot 5$ & $4 \cdot 2$ & $1 \cdot 4$ & 0.2 & 60 & $2 \cdot 7$ & $5 \cdot 1$ & $1 \cdot 6$ & $6 \cdot 3$ & $2 \cdot 8$ & $5 \cdot I$ & $1 \cdot 5$ \\
\hline $4 \cdot 9$ & $3 \cdot 1$ & 1.5 & 0.2 & $5 \cdot 4$ & 30 & $4 \cdot 5$ & $1 \cdot 5$ & $6 \cdot 1$ & $2 \cdot 6$ & $5 \cdot 6$ & $1 \cdot 4$ \\
\hline $5 \cdot 0$ & $3 \cdot 2$ & 1.2 & 0.2 & 6.0 & $3 \cdot 4$ & 4.5 & $1 \cdot 6$ & $7 \cdot \hat{7}$ & $3 \cdot 0$ & $6 \cdot 1$ & $2 \cdot 3$ \\
\hline $5 \cdot 5$ & $3 \cdot 5$ & $1 \cdot 3$ & 0.2 & 6.7 & $3 \cdot 1$ & $4 \cdot 7$ & 1.5 & $6 \cdot 3$ & $3 \cdot 4$ & $5 \cdot 6$ & $2 \cdot 4$ \\
\hline 4.9 & $3 \cdot 6$ & $1 \cdot 4$ & 0.1 & $6 \cdot 3$ & $2 \cdot 3$ & $4 \cdot 4$ & $1 \cdot 3$ & $6 \cdot 4$ & $3 \cdot I$ & $5 \cdot 5$ & $\overline{1} \cdot \overline{8}$ \\
\hline $4 \cdot 4$ & $3 \cdot 0$ & $1 \cdot 3$ & 0.2 & $5 \cdot 6$ & 30 & $4 \cdot 1$ & $1 \cdot 3$ & 6.0 & $3 \cdot 0$ & $4 \cdot 8$ & $1 \cdot 8$ \\
\hline $5 \cdot 1$ & $3 \cdot 4$ & 1.5 & 0.2 & $5-5$ & $2 \cdot 5$ & $4 \cdot 0$ & $1 \cdot 3$ & 6.9 & $3 \cdot 1$ & $5 \cdot 4$ & $2 \cdot 1$ \\
\hline 5.0 & 3.5 & $1 \cdot 3$ & 0.3 & $5 \cdot 5$ & $2 \cdot 6$ & $4 \cdot 4$ & $1 \cdot 2$ & 6.7 & $3 \cdot 1$ & $5 \cdot 6$ & $2 \cdot 4$ \\
\hline 4.5 & $2 \cdot 3$ & $1 \cdot 3$ & 0.3 & $6 \cdot 1$ & 3.0 & $4 \cdot 6$ & $\mathrm{I} \cdot 4$ & $6 \cdot 9$ & $3 \cdot 1$ & $5 \cdot 1$ & $2 \cdot 3$ \\
\hline $4 \cdot 4$ & $3 \cdot 2$ & 1.3 & 0.2 & $5 \cdot 8$ & $2 \cdot 6$ & $4 \cdot 0$ & $1 \cdot 2$ & $5 \cdot 8$ & 2.7 & $5 \cdot 1$ & 1.9 \\
\hline $5 \cdot 0$ & $3 \cdot 5$ & $1 \cdot 6$ & $0 . \overline{6}$ & $5 \cdot 0$ & $2 \cdot 3$ & $3 \cdot 3$ & $1 \cdot \overrightarrow{0}$ & $6 \cdot 8$ & $3 \cdot 2$ & $5 \cdot 9$ & $2 \cdot 3$ \\
\hline $5 \cdot I$ & 3.8 & 1.9 & 0.4 & $5 \cdot 6$ & $2 \cdot 7$ & $4 \cdot 2$ & $1 \cdot 3$ & $6 \cdot 7$ & $3 \cdot 3$ & $5 \cdot 7$ & 2.5 \\
\hline $4 \cdot 8$ & 3.0 & $1 \cdot 4$ & $0 \cdot 3$ & $5 \cdot 7$ & $3 \cdot 0$ & $4 \cdot 2$ & $1 \cdot 2$ & $6 \cdot 7$ & 3.0 & $5 \cdot 2$ & $2 \cdot 3$ \\
\hline $5 \cdot 1$ & $3 \cdot 8$ & $1 \cdot 6$ & 0.2 & $5 \cdot 7$ & $2 \cdot 9$ & $4 \cdot 2$ & $1 \cdot \overline{3}$ & $6 \cdot 3$ & 2.5 & $5 \cdot 0$ & $1 \cdot 9$ \\
\hline $4 \cdot 6$ & $3 \cdot 2$ & $1 \cdot 4$ & $0 \cdot 2$ & $6 \cdot 2$ & $2 \cdot 9$ & $4 \cdot 3$ & $1 \cdot 3$ & 6.5 & $3 \cdot 0$ & $5 \cdot 2$ & $2 \cdot 0$ \\
\hline $5 \cdot 3$ & $3 \cdot 7$ & 1.5 & $0 \cdot 2$ & $5 \cdot 1$ & $2 \cdot 5$ & $3 \cdot 0$ & $1 \cdot 1$ & $6 \cdot 2$ & $3 \cdot 4$ & $5 \cdot 4$ & $2 \cdot 3$ \\
\hline 5.0 & $3 \cdot 3$ & $1 \cdot 4$ & $0 \cdot \overline{2}$ & $5 \cdot 7$ & $2 \cdot 8$ & $4 \cdot 1$ & $1 \cdot 3$ & $5 \cdot 9$ & 30 & $5 \cdot \overline{1}$ & 1.8 \\
\hline
\end{tabular}


Table II. Observed means for two species and their difference (cm.)

\begin{tabular}{|l|c|c|c|}
\hline & Versicolor & Setosa & Difference $(V-S)$ \\
\hline Sepal length $\left(x_{1}\right)$ & $\mathbf{5 . 9 3 6}$ & $5 \cdot 006$ & 0.930 \\
Sepal width $\left(x_{2}\right)$ & $2 \cdot 770$ & $\mathbf{3 . 4 2 8}$ & -0.658 \\
Petal length $\left(x_{3}\right)$ & $4 \cdot 260$ & 1.462 & $2 \cdot 798$ \\
Petal width $\left(x_{4}\right)$ & 1.326 & 0.246 & 1.080 \\
\hline
\end{tabular}

Table III. Sums of squares and products of four measurements, within species $\left(\mathrm{cm} .{ }^{2}\right)$

\begin{tabular}{|l|c|c|c|c|}
\hline & Sepal length & Sepal width & Petal length & Petal width \\
\hline Sepal length & $19 \cdot 1434$ & $9 \cdot 0356$ & $9 \cdot 7634$ & $3 \cdot 2394$ \\
Sepal width & $9 \cdot 0356$ & $11 \cdot 8658$ & $4 \cdot 6232$ & $2 \cdot 4746$ \\
Petal length & $9 \cdot 7634$ & $4 \cdot 6232$ & $12 \cdot 2978$ & $3 \cdot 8794$ \\
Petal width & $3 \cdot 2394$ & $2 \cdot 4746$ & 3.8794 & $2 \cdot 4604$ \\
\hline
\end{tabular}

which the ratio $D^{2} / S$ is greatest, by variation of the four coefficients $\lambda_{1}, \lambda_{2}, \lambda_{3}$ and $\lambda_{4}$ independently. This gives for each $\lambda$

or

$$
\begin{gathered}
\frac{D}{S^{2}}\left\{2 S \frac{\partial D}{\partial \lambda}-D \frac{\partial S}{\partial \lambda}\right\}=0 \\
\frac{1}{2} \cdot \frac{\partial S}{\partial \lambda}=\frac{S}{D} \frac{\partial D}{\partial \lambda}
\end{gathered}
$$

where it may be noticed that $S / D$ is a factor constant for the four unknown coefficients. Consequently, the coefficients required are proportional to the solutions of the equations

$$
\left.\begin{array}{l}
S_{11} \lambda_{1}+S_{12} \lambda_{2}+S_{13} \lambda_{3}+S_{14} \lambda_{4}=d_{1} \\
S_{12} \lambda_{1}+S_{22} \lambda_{2}+S_{23} \lambda_{3}+S_{24} \lambda_{4}=d_{2} \\
S_{13} \lambda_{1}+S_{23} \lambda_{2}+S_{33} \lambda_{3}+S_{34} \lambda_{4}=d_{3} \\
S_{14} \lambda_{1}+S_{24} \lambda_{2}+S_{34} \lambda_{3}+S_{44} \lambda_{4}=d_{4}
\end{array}\right\}
$$

If, in turn, unity is substituted for each of the differences and zero for the others, the solutions obtained constitute the matrix of multipliers reciprocal to the matrix of $S$; numerically we find:

Table IV. Matrix of multipliers reciprocal to the sums of squares and products within species $\left(\mathrm{cm} .^{-2}\right)$

\begin{tabular}{|l|r|r|r|r|}
\hline & Sepal length & Sepal width & Petal length & \multicolumn{1}{|c|}{ Petal width } \\
\hline Sepal length & 0.1187161 & -0.0668666 & -0.0816158 & 0.0396350 \\
Sepal width & -0.0668666 & 0.1452736 & 0.0334101 & -0.1107529 \\
Petal length & $-0 \cdot 0816158$ & 0.0334101 & 0.2193614 & -0.2720206 \\
Petal width & 0.0396350 & -0.1107529 & -0.2720206 & 0.8945506 \\
\hline
\end{tabular}

These values may be denoted by $s_{p q}$ for values of $p$ and $q$ from 1 to 4 . 


\section{MULTTPLE MEASUREMENTS IN TAXONOMIC PROBLEMS}

Multiplying the columns of the matrix in Table IV by the observed differences, we have the solutions of the equation (1) in the form

$$
\lambda=-0.0311511, \quad \lambda_{2}=-0.1839075, \quad \lambda_{3}=+0.2221044, \quad \lambda_{4}=+0.3147370,
$$

so that, if we choose to take the coefficient of sepal length to be unity, the compound measurement required is

$$
X=x_{1}+5 \cdot 9037 x_{2}-7 \cdot 1299 x_{3}-10 \cdot 1036 x_{4} .
$$

If in this expression we substitute the values observed in setosa plants, the mean, as found from the values in Table $I$, is

$$
5 \cdot 006+(3 \cdot 428)(5 \cdot 9037)-(1 \cdot 462)(7 \cdot 1299)-(0 \cdot 246)(10 \cdot 1036)=12 \cdot 3345 \mathrm{~cm},
$$

for versicolor, on the contrary, we have

$$
5.936+(2 \cdot 770)(5 \cdot 9037)-(4 \cdot 260)(7 \cdot 1299)-(1.326)(10 \cdot 1036)=-21.4815 \mathrm{~cm} .
$$

The difference between the average values of the compound measurements being thus $33.816 \mathrm{~cm}$.

The distinctness of the metrical characters of the two species may now be gauged by comparing this difference between the average values with its standard error. Using the values of Table III, with the coefficients of our compound, we have

$$
\begin{aligned}
& 19 \cdot 1434+(9 \cdot 0356)(5 \cdot 9037)-(9 \cdot 7634)(7 \cdot 1299)-(3 \cdot 2394)(10 \cdot 1036)=-29 \cdot 8508 \text {, } \\
& 9 \cdot 0356+(11.8658)(5.9037)-(4 \cdot 6232)(7.1299)-(2 \cdot 4746)(10.1036)=21 \cdot 1224 \text {, } \\
& 9 \cdot 7634+(4 \cdot 6232)(5 \cdot 9037)-(12 \cdot 2978)(7 \cdot 1299)-(3 \cdot 8794)(10 \cdot 1036)=-89 \cdot 8206 \text {, } \\
& 3.2394+(2 \cdot 4746)(5 \cdot 9037)-(3 \cdot 8794)(7 \cdot 1299)-(2 \cdot 4604)(10 \cdot 1036)=-34 \cdot 6699,
\end{aligned}
$$

and finally,

$$
-29 \cdot 8508+(21 \cdot 1224)(5 \cdot 9037)+(89 \cdot 8206)(7 \cdot 1299)+(34 \cdot 6699)(10 \cdot 1036)=1085 \cdot 5522 .
$$

The average variance of the two species in respect of the compound measurements may be estimated by dividing this value $(1085.5522)$ by 95 ; the variance of the difference between two means of fifty plants each, by dividing again by 25. For single plants the variance is 11.4269 , so that the mean difference, $33.816 \mathrm{~cm}$., between a pair of plants of different species has a standard deviation of $4.781 \mathrm{~cm}$. For means of fifty the same average difference has the standard error $0.6761 \mathrm{~cm}$., or only about one-fiftieth of its value.

\section{INTERPRETATION}

The ratio of the difference between the means of the chosen compound measurement to its standard error in individual plants is of interest also in relation to the probability of misclassification, if the specific nature were judged wholly from the measurements. For reasons to be discussed later we shall estimate the variance of a single plant by dividing 1085.5522 by 95 , giving $11.4269 \mathrm{~cm}^{2}$ for the variance, and $3.3804 \mathrm{~cm}$. for the standard deviation. Supposing that a plant is misclassified, if its deviation in the right direction 
exceeds half the difference, $33.816 \mathrm{~cm}$., between the species, the ratio to the standard as estimated is $5 \cdot 0018$.

The table of the normal distribution (Statistical Methods, 'lable II) shows that a ratio 4.89164 is exceeded five times in a million, and 5.32672 only once in two million trials. By logarithmic interpolation the frequency appropriate to a ratio 5.0018 is about 2.79 per million. If the variances of the two species are unequal, this frequency is somewhat overestimated by this method, since we ought to divide the specific difference in proportion to the two standard deviations, and for constant sum of variances the sum of the standard deviations is greatest when they are equal. We may, therefore, at once conclude that if the measurements are nearly normally distributed the probability of misclassification, using the compound measurement only is less than three per million.

The same ratio is of interest from another aspect. If the chosen compound $X$ is analysed in respect to its variation within and between species, the sum of squares between species must be $25 D^{2}$. Numerically we have, therefore,

Table V. Analysis of variance of the chosen compound $X$, between and within species

\begin{tabular}{|l|c|c|}
\hline & $\begin{array}{c}\text { Degrees of } \\
\text { freedom }\end{array}$ & Sum of squares \\
\hline $\begin{array}{l}\text { Between species } \\
\text { Within species }\end{array}$ & 4 & $\begin{array}{c}28588.05 \\
1085 \% 55\end{array}$ \\
\hline Total & 99 & 29673.60 \\
\hline
\end{tabular}

Of the total only 3.6583 per cent. is within species, and $96 \cdot 3417$ per cent. between species. The compound has been chosen to maximize the latter percentage. Since, in addition to the specific means, we have used three adjustable ratios, the variation within species must contain only 95 degrees of freedom.

In making up the variate $X$, we have multiplied the original values of $\lambda$ by $-32 \cdot 1018$ in order to give to the measurement sepal length the coefficient unity. Had we used the original values, the analysis of Table $V$ would have appeared as:

Table VI. Analysis of variance of the crude compound $X$, between and within species

\begin{tabular}{|c|c|c|c|}
\hline & $\begin{array}{c}\text { Degrees of } \\
\text { freedom }\end{array}$ & $\begin{array}{c}\text { Sum of } \\
\text { squares }\end{array}$ & \\
\hline $\begin{array}{l}\text { Between species } \\
\text { Within species }\end{array}$ & $\begin{array}{c}4 \\
\text { Total }\end{array}$ & $\begin{array}{c}27 \cdot 74160 \\
1 \cdot 05341\end{array}$ & $\begin{array}{l}=25 D^{2} \\
=D=S\end{array}$ \\
\hline 9 & $28 \cdot 79501$ & $D(1+25 D)$ \\
\hline
\end{tabular}

On multiplying equations (1) by $\lambda_{1}, \lambda_{2}, \lambda_{3}$ and $\lambda_{4}$ and adding, it appears that $S=\Sigma \lambda d=D$, the specific difference in the crude compound $X$. The proportion ( $3 \cdot 6$ per cent.) of the sum of squares within species could therefore have been found simply as $1 /(1+25 D)$. 


\section{The aNalogi of Partial Regression}

The analysis of Table VI suggests an analogy of some interest. If to each plant were assigned a value of a variate $y$, the same for all members of each species, the analysis of variance of $y$, between the portions accountable by linear regression on the measurements $x_{1}, \ldots, x_{4}$, and the residual variation after fitting such a regression, would be identical with Table VI, if $y$ were given appropriate equal and opposite values for the two species.

In general, with different numbers of representatives of the two species, $n_{1}$ and $n_{2}$, if the values of $y$ assigned were

$$
\frac{n_{2}}{n_{1}+n_{2}} \text { and } \frac{-n_{1}}{n_{1}+n_{2}}
$$

differing by unity, the right-hand sides of the equations for the regression coefficients, corresponding to equation (1), would have been

$$
\frac{n_{1} n_{2}}{n_{1}+n_{2}} d_{p}
$$

where $d_{p}$ is the difference between the means of the two species in any one of the measurements. The typical coefficient of the left-hand side would be

$$
S_{p q}+\frac{n_{1} n_{2}}{n_{1}+n_{2}} d_{p} d_{q}
$$

Transferring the additional fractions to the right-hand side, we should have equations identical with (1), save that the right-hand sides are now

$$
\frac{n_{1} n_{2}}{n_{1}+n_{2}} d_{p}\left(1-\Sigma \lambda^{\prime} d\right)
$$

where $\lambda^{\prime}$ stands for a solution of the new equations; hence

$$
\lambda^{\prime}=\frac{n_{1} n_{2}}{n_{1}+n_{2}}\left(1-\sum \lambda^{\prime} d\right) \lambda
$$

multiply these equations by $d$ and add, so that

or

$$
\begin{gathered}
\Sigma \lambda^{\prime} d=\frac{n_{1} n_{2}}{n_{1}+n_{2}} \Sigma \lambda d\left(1-\Sigma \lambda^{\prime} d\right) \\
\left(1-\Sigma \lambda^{\prime} d\right)\left(1+\frac{n_{1} n_{2}}{n_{1}+n_{2}} \Sigma \lambda d\right)=1 \\
1-\Sigma \lambda^{\prime} d=\frac{1}{1+25 D} .
\end{gathered}
$$

and so in our example

The analysis of variance of $y$ is, therefore,

Table VII. Analysis of variance of a variate $y$ determined exclusively by the species

\begin{tabular}{|c|c|c|c|}
\hline & $\begin{array}{c}\text { Degrees of } \\
\text { freedom }\end{array}$ & $\begin{array}{c}\text { Sum of } \\
\text { squares }\end{array}$ & \\
\hline Regression & 4 & $\begin{array}{c}24 \cdot 0854 \\
0.9146\end{array}$ & $\begin{array}{l}25^{2} D / 1+25 D \\
25 / 1+25 D\end{array}$ \\
\hline Remainder & 95 & $25 \cdot 0000$ & \\
\hline Total & 99 & 000 & \\
\hline
\end{tabular}


The total $S\left(y^{2}\right)$ is clearly in general $\frac{n_{1} n_{2}}{n_{1}+n_{2}}$; the portion ascribable to regression is

$$
\frac{n_{1} n_{2}}{n_{1}+n_{2}} \Sigma \lambda^{\prime} d=\frac{25^{2} D}{1+25 D} \text {. }
$$

In this method of presentation the appropriate allocation of the degrees of freedom is evident.

The multiple correlation of $y$ with the measurements $x_{1}, \ldots, x_{4}$ is given by

$$
R^{2}=25 D / 1+25 D \text {. }
$$

\section{Test of significance}

It is now clear in what manner the specific difference may be tested for significance, so as to allow for the fact that a variate has been chosen so as to maximise the distinctness of the species. The regression of $y$ on the four measurements is given 4 degrees of freedom, and the residual variation 95 ; the value of $z$ calculated from the sums of squares in any one of Tables V, VI or VII is 3.2183 or

$$
\frac{1}{2}(\log 95-\log 4+\log 25+\log D),
$$

a very significant value for the number of degrees of freedom used.

\section{Applications to the theory of allopolyploidy}

We may now consider one of the extensions of this procedure which are available when samples have been taken from more than two populations. The sample of the third species given in Table I, Iris virginica, differs from the two other samples in not being taken from the same natural colony as they were - a circumstance which might considerably disturb both the mean values and their variabilities. It is of interest in association with $I$. setosa and $I$. versicolor in that Randoph (1934) has ascertained and Anderson has confirmed that, whereas $I$. setosa is a "diploid" species with 38 chromosomes, I. virginica is "tetraploid", with 70 , and $I$. versicolor, which is intermediate in three measurements, though not in sepal breadth, is hexaploid. He has suggested the interesting possibility that $I$. versicolor is a polyploid hybrid of the two other species. We shall, therefore, consider whether, when we use the linear compound of the four measurements most appropriate for discriminating three such species, the mean value for $I$. versicolor takes an intermediate value, and, if so, whether it differs twice as much from $I$, setosa as from $I$. virginica, as might be expected, if the effects of genes are simply additive, in a hybrid between a diploid and a tetraploid species.

If a third value lies two-thirds of the way from one value to another, the three deviations from their common mean must be in the ratio $4: 1:-5$. To obtain values corresponding with the differences between the two species we may, therefore, form linear compounds of their mean measurements, using these numerical coefficients. The results are shown in Table VIII where, for example, the value $7.258 \mathrm{~cm}$. for sepal length is four times the mean 
sepal length for $I$. virginica plus once the mean sepal length for $I$. versicolor minus five times the value for $I$. setosa.

Table VIII

\begin{tabular}{|c|c|c|c|c|}
\hline Means & \multicolumn{4}{|c|}{$s_{p q}$} \\
\hline \multicolumn{5}{|c|}{ Iris virginica. Fifty plants } \\
\hline $\begin{array}{l}6 \cdot 588 \\
2 \cdot 974 \\
5 \cdot 552 \\
2 \cdot 026\end{array}$ & $\begin{array}{r}19 \cdot 8128 \\
4.5944 \\
14 \cdot 8612 \\
2 \cdot 4056\end{array}$ & $\begin{array}{l}4 \cdot 5944 \\
5 \cdot 0962 \\
3 \cdot 4976 \\
2 \cdot 3338\end{array}$ & $\begin{array}{r}14 \cdot 8612 \\
3 \cdot 4976 \\
14 \cdot 9248 \\
2 \cdot 3924\end{array}$ & $\begin{array}{l}2 \cdot 4056 \\
2 \cdot 3338 \\
2-3924 \\
3 \cdot 6962\end{array}$ \\
\hline \multicolumn{5}{|c|}{ Iris versicolor. Fifty plants } \\
\hline $\begin{array}{l}5 \cdot 936 \\
2 \cdot 770 \\
4 \cdot 260 \\
I \cdot 326\end{array}$ & $\begin{array}{r}13 \cdot 0552 \\
4 \cdot 1740 \\
8 \cdot 9620 \\
2 \cdot 7332\end{array}$ & $\begin{array}{l}4 \cdot 1740 \\
4 \cdot 8250 \\
4 \cdot 0500 \\
2 \cdot 0190\end{array}$ & $\begin{array}{r}8.9620 \\
4.0500 \\
10 \cdot 8200 \\
3 \cdot 5820\end{array}$ & $\begin{array}{l}2 \cdot 7332 \\
2 \cdot 0190 \\
3 \cdot 5820 \\
1 \cdot 9162\end{array}$ \\
\hline \multicolumn{5}{|c|}{ Iris setosa. Fifty plants } \\
\hline $\begin{array}{l}5.006 \\
3.428 \\
1.462 \\
0.246\end{array}$ & $\begin{array}{l}6 \cdot 0882 \\
\mathbf{4} \cdot 8616 \\
0 \cdot 8014 \\
0.5062\end{array}$ & $\begin{array}{l}4.8616 \\
7.0408 \\
0.5732 \\
0.4556\end{array}$ & $\begin{array}{l}0.8014 \\
0.5732 \\
1.4778 \\
0.2974\end{array}$ & $\begin{array}{l}0.5062 \\
0.4556 \\
0.2974 \\
0.5442\end{array}$ \\
\hline \multicolumn{5}{|c|}{$4 v i+v e-5 s e$} \\
\hline $\begin{array}{r}7 \cdot 258 \\
-2 \cdot 474 \\
19 \cdot 158 \\
8 \cdot 200\end{array}$ & $\begin{array}{r}482 \cdot 2650 \\
199 \cdot 2244 \\
266 \cdot 7762 \\
53 \cdot 8778\end{array}$ & $\begin{array}{r}199 \cdot 2244 \\
262 \cdot 3842 \\
74 \cdot 3416 \\
50 \cdot 7498\end{array}$ & $\begin{array}{r}266 \cdot 7762 \\
74 \cdot 3416 \\
286 \cdot 5618 \\
49 \cdot 2954\end{array}$ & $\begin{array}{c}53 \cdot 8778 \\
50 \cdot 7498 \\
49 \cdot 2954 \\
74 \cdot 6604\end{array}$ \\
\hline
\end{tabular}

Since the values for the sums of squares and products of deviations from the means within each of the three species are somewhat different, we may make an appropriate matrix corresponding with our chosen linear compound by multiplying the values for I. virginica by 16 , those for $I$. versicolor by one and those for $I$. selosa by 25 , and adding the values for the three species, as shown in Table VIII. The values so obtained will correspond with the matrix of sums of squares and products within species when only two populations have been sampled.

Using the rows of the matrix as the coefficients of four unknowns in an equation with our chosen compound of the mean measurements, e.g.

$$
482 \cdot 2650 \lambda_{1}+199 \cdot 2244 \lambda_{2}+266 \cdot 7762 \lambda_{3}+53 \cdot 8778 \lambda_{4}=7 \cdot 258,
$$

we find solutions which, when multiplied by 100 , are

$$
\begin{array}{rr}
\text { Coefficient of sepal length } & -3.308998 \\
\text { sepal breadth } & -2.759132 \\
\text { petal length } & 8.866048 \\
\text { petal breadth } & 9.392551
\end{array}
$$

defining the compound measurement required. 
It is now easy to find the means and variances of this compound measurement in the three species. These are shown in the table below (Table $\mathrm{TX}$ ):

Table IX

\begin{tabular}{|l|r|c|c|c|}
\hline & Mean & $\begin{array}{c}\text { Sum of } \\
\text { squares }\end{array}$ & $\begin{array}{c}\text { Mean } \\
\text { square }\end{array}$ & $\begin{array}{c}\text { Standard } \\
\text { deviation }\end{array}$ \\
\hline I. virginica & $38 \cdot 24827$ & $923 \cdot 7958$ & $\mathbf{1 8} \cdot 8530$ & $\mathbf{4} \cdot \mathbf{3 4 2}$ \\
I. versicalor & 22.93888 & $873 \cdot 519$ & $\mathbf{1 7 \cdot 8 2 6 8}$ & $\mathbf{4} \cdot \mathbf{2 2 2}$ \\
I. setosa & $-\mathbf{1 0} \cdot 75042$ & $\mathbf{2 9 2 \cdot 8 9 5 8}$ & $\mathbf{5} \cdot 9775$ & $2 \cdot 444$ \\
\hline
\end{tabular}

From this table it can be seen that, whereas the difference between $I$. setosa and $I$. versicolor, 33.69 of our units, is so great compared with the standard deviations that no appreciable overlapping of values can occur, the difference between $I$, virginica and I. versicolor, 15.31 units, is less than four times the standard deviation of each species.

The differences do seem, however, to be remarkably closely in the ratio $2: 1$. Compared with this standard, I. virginica would appear to have exerted a slightly preponderant influence. The departure from expectation is, however, small, and we have the material for making at least an approximate test of significance.

If the differences between the means were exactly in the ratio $2: 1$, then the linear function formed by adding the means with coefficients in the ratio $2:-3: 1$ would be zero. Actually it has the value 3.07052 . The sampling variance of this compound is found by multiplying the variances of the three species by 4,9 and 1 , adding them together and dividing by 50 , since each mean is based on fifty plants. This gives 4.8365 for the variance and $2 \cdot 199$ for the standard error. Thus on this test the discrepancy, $3 \cdot 071$, is certainly not significant, though it somewhat exceeds its standard error.

In theory the test of significance is not wholly exact, since in estimating the sampling variance of each species we have divided the sum of squares of deviations from the mean by 49 , as though these deviations had in all 147 degrees of freedom. Actually three degrees of freedom have been absorbed in adjusting the coefficients of the linear compound so as to discriminate the species as distinctly as possible. Had we divided by 48 instead of by 49 the standard error would have been raised by a trifle to the value $2 \cdot 231$, which would not have affected the interpretation of the data. This change, however, would certainly have been an over-correction, since it is the variances of the extreme species $I$. virginica and $I$. setosa which are most reduced in the choice of the compound measurement, while that of $I$. versicolor contributes the greater part of the sampling error in the test of significance.

The diagram, Fig. 1, shows the actual distributions of the compound measurement adopted in the individuals of the three species measured. It will be noticed, as was anticipated above, that there is some overlap of the distributions of $I$. virginica and I. versicolor, so that a certain diagnosis of these two species could not be based solely on 
these four measurements of a single flower taken on a plant growing wild. It is not, however, impossible that in culture the measurements alone should afford a more complete discrimination.

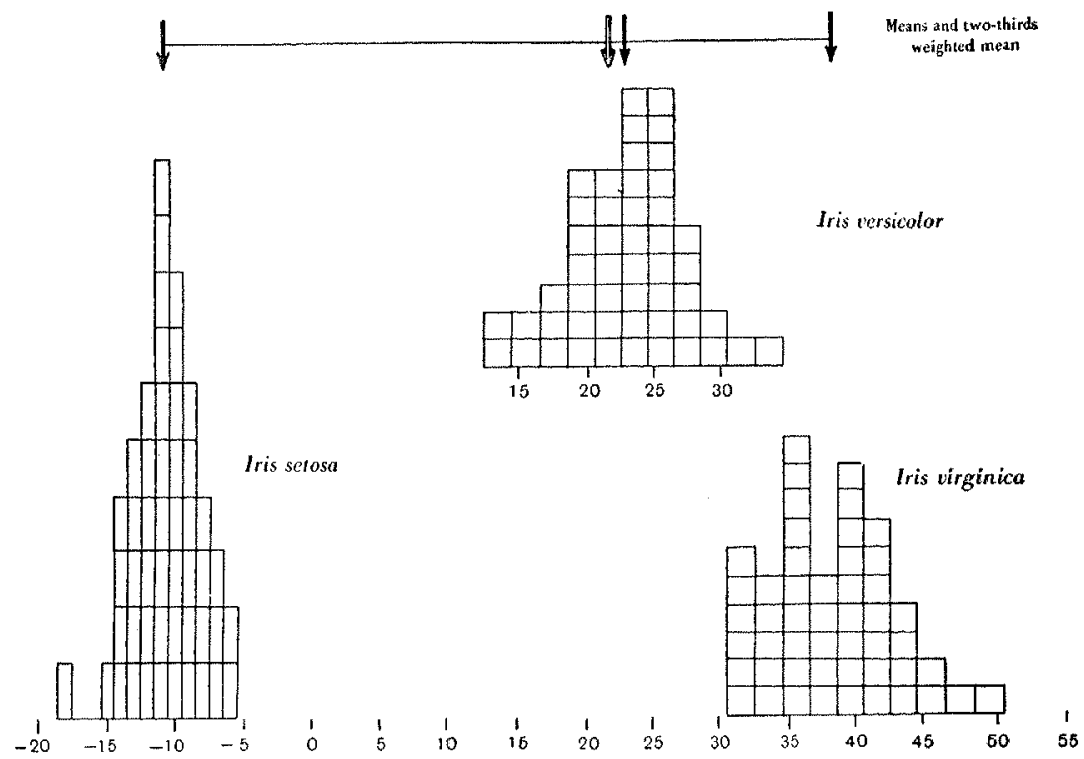

Fig. 1. Frequency histograms of the discriminating linear function, for three species of Iris.

\section{REFERENCES}

RaNDOLrI, L. F. (1934). "Chromosome numbers in native American and introduced species and cultivated varieties of Iris." Bull. Amer. Iris Soc. 52, 61-66.

Anderson, Edgar (1935). "The irises of the Gaspe Peninsula." Bull. Amer. Iris Soc. 58, 2-5.

- (1936). "The species problem in Iris." Ann. Mo. bot. Giln. (in the Press). 